DOI: $10.14451 / 2.123 .73$

\title{
МОДЕЛИРОВАНИЕ РАЗВИТИЯ СФЕРЫ УСЛУГ
}

\author{
(c) 2018 Рябова Елена Валентиновна \\ доктор экономических наук, профессор \\ Санкт-Петербургский университет технологий управления и экономики \\ г. Санкт-Петербург, Лермонтовский просп., 44 \\ E-mail: thtk.05@mail.ru \\ (c) 2018 Сосунова Лильяна Алексеевна \\ доктор экономических наук, профессор \\ Самарский государственный экономический университет \\ 443090, г. Самара, ул. Советской Армии, д. 141 \\ E-mail: kafedra-kl@yandex.ru \\ (c) 2018 Мухаметзянова Лилия Халиловна \\ кандидат экономические наук, доцент \\ Самарский государственный экономический университет \\ 443090, г. Самара, ул. Советской Армии, д. 141 \\ E-mail: givanchygirl@mail.ru
}

В статье рассмотрены особенности развития сферы услуг в условиях стратегических изменений. Предложен алгоритм моделирования и развития сферы услуг, представлена характеристика и взаимосвязь параметров модели.

Ключевые слова: сфера услуг, моделирование сферы услуг, стратегические изменения.

Сложность современных экономических условий, в которых осуществляют свою деятельность предприятия сферы услуг, определена нарастающей неопределенностью, быстро меняющейся конъюнктурой и внешней средой. В связи с чем, более остро признается необходимость обеспечения и развития адаптационных способностей предприятия на длительный период, что, в свою очередь, определяет важность осуществления стратегических изменений.

Рассматривая процесс изменений и управленческое воздействие, т.е. как управленческая деятельность участвует в процессе реализации этапов преобразований в рамках функциональной концепции, следует отметить, что

это позволяет изучать и применять более детальные и приближенные к практике аспекты управления стратегическими изменениями, не теряя общего системного понимания.

Разработка концептуальных основ развития сферы услуг в условиях стратегических изменений предполагает формулировку стратегических целей, задач, выбор приоритетных направлений развития, а также совершенствование процесса управления на основе функционального подхода, где все управленческие действия могут быть проконтролированы как в процессе осуществле- ния, так и через анализ их результатов.

Рассмотрим подробнее экономический механизм развития сферы услуг и представим модель функционально-ориентированного управления стратегическими изменениями на предприятиях сферы услуг, которая будет направлена на оптимизацию функций, реализуемых при проведении стратегических изменений.

Функционально-ориентированное управление стратегическими изменениями обеспечивает такое положение, когда решения менеджеров любого звена принимаются в полном соответствии с последовательной стратегией всего предприятия, а также помогает обеспечить преемственность в период преобразований. Непосредственно осуществление изменений начинается, когда на предприятии принимается решение об обязательности перемен и формируются соответствующие общие цели. Далее начинается работа с применением основного инструментария менеджера, а именно функций управления (выполнение основных видов управленческой деятельности). Последовательность, в которой они представлены выше, соответствует общей очередности применения функций в рамках решения какой-либо проблемы: формулирование цели, планирование деятельности и 
так далее до контроля, который осуществляется вплоть до решения задач.

В связи с тем, что главная задача состоит из более мелких и для каждой определен свой процесс решения с обозначением целей, подготовкой плана и т.п., и при этом реализация отдельных функций носит постоянный, либо цикличный характер, что позволяет судить о том, что в каждый конкретный момент времени для предприятия в целом важны и активны все функции управления.

Таким образом, выполнение и завершение трансформации подтверждаются не прохождением контрольной стадии, а той управленческой процедурой, которая используется для организации работ. Так, имеется в виду, что если преобразование не было завершено, но формально система констатирует данный факт, то вероятнее всего, изменение будет завершено.

Детализированное выражение зависимости представим в виде формулы.

$$
y=f\left(K_{1}, K_{2}, \ldots K_{n}\right),
$$

где $\mathrm{K}_{1} \ldots . \mathrm{K}_{\mathrm{n}}$ - интегральные значения компонентов.

Приведенные выше рассуждения не означают, что последовательность выполнения функций не связана с прогрессом:

- целеполагание, планирование и прогнозирование обычно осуществляются на начальном этапе, а пересмотр планов и целей определяет начало нового цикла;

- распорядительство и организация также характерны в большей степени для начального этапа, но могут быть реализованы при осуществлении функции контроля, что происходит в рамках решения проблем и корректировки плана;

- координация, мотивация, учет, реализуются постоянно - как ситуационно, так и регламентируемо;

- контроль и анализ проводятся постоянно - как регулярно, в рамках обозначенных процедур, так и нерегулярно, по мере необходимости.

Интегральное значение коэффициентов обеспечения процесса реализации функций управления определим по следующей формуле:

$$
K_{\text {uнm }}=\sqrt[n]{K 1 \cdot K 2 \cdot K 3 \cdot K 4 \cdot K n}
$$

Для более полной оценки уровня реализации функций управления стратегическими изменениями, помимо интегральных коэффициентов инфраструктурных компонентов, следует дополнительно рассчитывать интегральные значения коэффициентов.

Следующий этап разработки модели включает в себя расчет показателей методом наименьших квадратов с целью аналитического выравнивания эмпирических показателей, что предполагает нахождение такого теоретического уровня, который удовлетворял бы следующим двум условиям.

1. Сумма линейных отклонений теоретических значений ряда от эмпирических равна нулю: $\sum=(\breve{y}-\mathrm{y})=0$.

2. Сумма квадратов указанных отклонений есть величина наименьшая:

$$
\sum=(\breve{y}-y)^{2}=\min
$$

Для нахождения коэффициентов факторного уравнения построим систему нормальных уравнений:

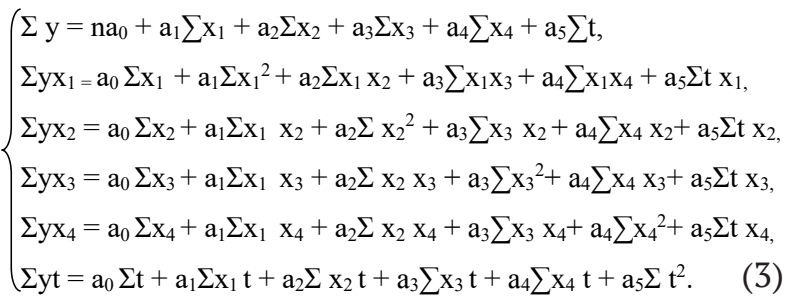

Решение системы уравнений с помощью программной разработки «Расчет n-факторной регрессионной модели» на основе Mathcad Professional позволяет получить модель оценки уровня взаимосвязи функции организации и инфраструктурных компонентов управления стратегическими изменениями на предприятии сферы услуг (где $\mathrm{n}$ - расчетное число):

$$
Y^{`}=n+n x_{1}+n x_{2}+n x_{3}+n x_{4}+n t
$$

Представленная модель показывает, что наибольшее влияние на уровень реализации оказывает конкретная функция.

Правильность расчетов подтверждают тем, что коэффициент множественной корреляции равен 1:

$$
R=\sqrt{1-\frac{\sum\left(y-y_{p a c}\right)^{2}}{\sum\left(y-y_{c p}\right)^{2}}}
$$


Близость коэффициента корреляции к 1 позволяет судить о надежности модели и о существовании связи между переменными.

После построения модели, на наш взгляд, необходимо провести оценку ее значимости и достоверности на основе применения различных статистических характеристик.

Проверку полученной модели на величину ошибки, получаемой при ее использовании в процессе осуществления оценки уровня взаимосвязи функции и инфраструктурных компонентов управления стратегическими изменениями на предприятии сферы услуг, можно осуществить с помощью проведения ретроспективного прогнозирования.

Таким образом, все вышеприведенные статистические взаимосвязи свидетельствуют о том, что предлагаемая модель обеспечивает получение достоверных оценок используемых показателей, искомые данные по этой модели приблизительно равны фактическим показателям и правильно отражают тенденцию изменений. Следовательно, совершенствование отдельных компонентов процесса реализации функции управления способствует повышению уровня ее выполнения в целом.

\section{Библиографический список:}

1. Курский В.А. Композиционная модель эволюционного развития предприятия как инструмент стратегического управления [Текст] / В.А. Курский // Финансы и кредит. 2012. № 20. С. 24-27.

2. Рябова Е.В. Природа и причины возникновения стратегических изменений в экономических системах // Межвузовский сб. науч. статей Экономика, финансы и управление в современных условиях. 2011. № 7 (9).

3. Сосунова Л.А. Сервисная деятельность на интегрированном рынке [Текст]: учеб. пособие / Л.А. Сосунова, Н.У. Казачун, С.М. Хаирова. - Самара. 2006. 80 с.

4. Чернова Д.В. Основные тенденции развития услуг в экономике России [Текст] / Д.В. Чернова, Л.А. Сосунова // Логистика, бизнес-статистика, сервис: проблемы научных исследований и подготовки специалистов: материалы Междунар. науч.-практ. конф. 22-24 мая 2006 г. Самара. 2006.

5. Чернышев Б. Менеджмент в сервисной экономике: сущность и содержание // Проблемы теории и практики управления. 2014. № 1. С. 64-71.

6. Greenfield F.L.Y. Manpower and the Growth of Producer Services. New York - London. 2009. P. 43-81.

7. Haggerty P.E. Strategies, Tactics and Research [Text] // Research Management. 2012. № 2. P. 141-159. 